the surface of a planet, which could provide a solvent for prebiotic chemistry. Kasting's habitable zone is often couched as a Goldilocks story: planets capable of hosting life must be neither too hot such that liquid water evaporates, nor too cold such that it freezes, but just right, allowing liquid water. In our Solar System, Earth sits snugly inside the inner boundary of Kasting's habitable zone, whereas Venus orbits too close to the Sun, dooming our near twin to be waterless and lifeless.

The case of Mars illustrates that there is more to habitability than a planet's distance from a star. Freezing temperatures render the red planet lifeless today. But there is evidence that liquid water once flowed on its surface, sculpting gullies and river beds. Impact craters from the heavy bombardment period of the Solar System overlay these twisting features, dating them to at least 3.8 billion years ago.

Kasting notes that this interpretation of the surface morphology on Mars is not universally accepted, but it is appealing. The possibility of a liquid-water phase in the planet's history raises the question of whether life might have had an early start there with a thicker atmosphere that trapped heat. Any surface water has long since evaporated because the planet was too puny to hang on to its atmosphere.

In recent years we have progressed from being able to detect only massive gas giants around other stars to discovering a handful of smaller rocky worlds a few times the mass of Earth. Kasting reviews the astronomical techniques involved. Ground-based telescopes can detect a planet through its influence on the motion of the parent star, revealed through Doppler velocity shifts and changes in the timing of pulsar flashes for neutron stars, or through brightness changes caused by gravitational microlensing and planetary transits.

From space, the Kepler mission, which launched in 2009, is now taking a census of stars to determine the fraction that have

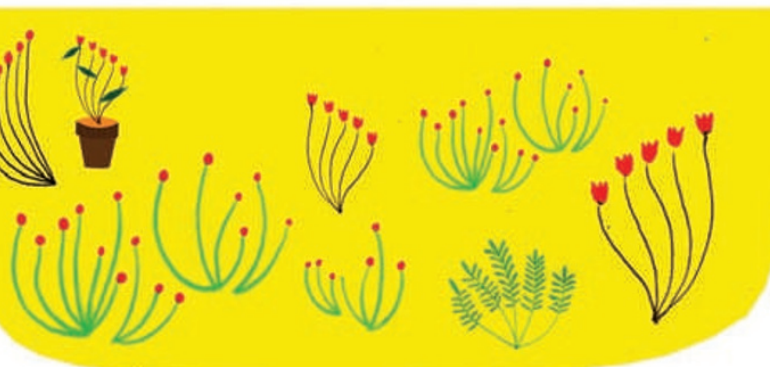

Kasting deftly charts a course through planet formation, detection and geochemistry to introduce readers to what is likely to be the next big discovery: the detection of oxygen, water or methane in the atmospheres of exoplanets, signalling the possibility of life. Challenging the notion that life elsewhere is rare, he makes a strong case that simple life forms will contaminate atmospheres in ways that are spectroscopically detectable. But he cautions that abiotic sources of oxygen and methane can lead to false positives.

The key will be finding a convincing set of conditions. For Kasting, finding both liquid water on the surface and oxygen in the atmosphere would be enough. "I would be 99 per cent sure that life was present if I saw this combination of planetary characteristics," he says. Such signatures of life could be detected in the coming decades.

Earth-sized planets. The Hubble Space Telescope has detected abiotic atmospheric features on other planets, such as water and methane derived from physical processes, and the Spitzer Space Telescope has measured wind speeds in gas-giant exoplanets. Future missions will measure the mass and orbits of Earth-like planets and trace the motions of clouds.
How to Find a Habitable Planet will fascinate those who care about the evolution of Earth's climate and wonder about how we will eventually detect life - even simple cellular life elsewhere.

Debra Fischer is professor of astronomy at Yale University, New Haven, Connecticut 06511, USA. e-mail:debra.fischer@yale.edu

\title{
Education as a global commodity
}

\section{The Great Brain Race: How Global \\ Universities Are Reshaping the World by Ben Wildavsky \\ Princeton University Press: 2010. 248 pp. $\$ 26.95, £ 18.95$}

Globalization is rapidly changing both the way universities operate and the idea of what a university is. In particular, there is increasing worldwide competition for the best students and scholars, and an expanding global market for educational credentials. In The Great Brain Race, journalist Ben Wildavsky, a former education editor of the U.S. News and World Report college rankings, argues that this is as an opportunity rather than a threat and urges universities to embrace globalization "not with fear but with a sense of possibility".

Wildavsky examines five aspects of globalization in higher education: the increasing mobility

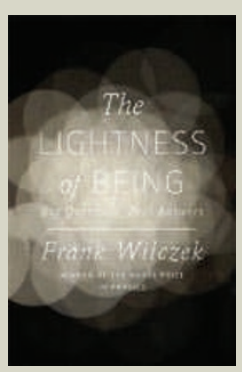

The Lightness of Being: Big Questions, Real Answers

by Frank Wilczek (Penguin, $€ 9.99$ )

Our understanding of the essential nature of reality has changed dramatically in recent decades. In The Lightness of Being, physicist Frank Wilczek presents a clear synthesis of modern physics, pointing to areas in which fundamental discoveries are likely, including particle physics. He articulates a vision for a new 'golden age' in physics.

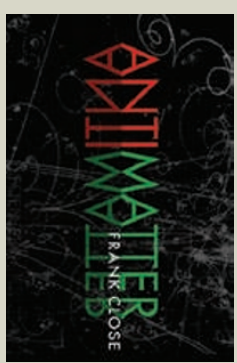

\section{Antimatter}

by Frank Close (Oxford Univ. Press, $€ 7.99$ ) Antimatter explores a strange mirror world where particles have identical yet opposite properties to those that make up the matter we encounter daily; a world where left becomes right and positive becomes negative. Frank Close separates the facts from the fiction about antimatter, and explains how its existence gives profound clues about the origins and structure of the Universe. 
of students and scholars across international borders; the establishment of university branch campuses in foreign countries; the race to build world-class research institutions focusing on science and technology; the proliferation of global college rankings; and the growth of for-profit education service providers that compete with traditional universities for students, faculty and revenue. Higher education, he observes, "has become a form of international trade", a global marketplace advancing a "free trade in minds".

Wildavsky decries all forms of "protectionism" in higher education, such as policies that prioritize the admission of students from an institution's home country, and opposes affirmative-action programmes, such as India's 'reservation' system for 'scheduled castes'. He endorses instead a meritocratic system in higher education. He admits that most educational shoppers in today's global supermarket of universities come from elite families, but insists that, over time, increasing mobility will "undermine rather than reinforce elites based on inherited privilege and political pull".

"That the forces of
globalization will
profoundly shape
the future of higher
education cannot be
ignored."

The scope of change in global higher education is remarkable. Ventures such as the state-of-the-art King Abdullah University of Science and Technology in Saudi Arabia, India's rising Institutes of Technology, China's esteemed 'C9 League' of its nine top universities and Singapore's bid to become an international knowledge hub have all helped to make higher education a fast-changing, fiercely competitive global enterprise. Wildavsky argues that only the fittest will survive.

He tells an engaging story about the ways in which global universities are "reshaping the world" but downplays a key cause of current entrepreneurial trends in US higher education: decreasing public investment. University presidents, faculty senate members and professors have all spoken of the urgent need for their institutions to generate revenue from overseas to fill the funding gap. Wildavsky omits to say how reduced state investment is driving the globalization strategies of US universities compared with their equivalents in countries that are increasing public support.

Wildavsky's book shows how globalization has gone hand in hand with the de facto privatization of US universities. Nearly every aspect of the university has been commodified. The enrolment of international students is now factored into a global "balance of trade" in tuition

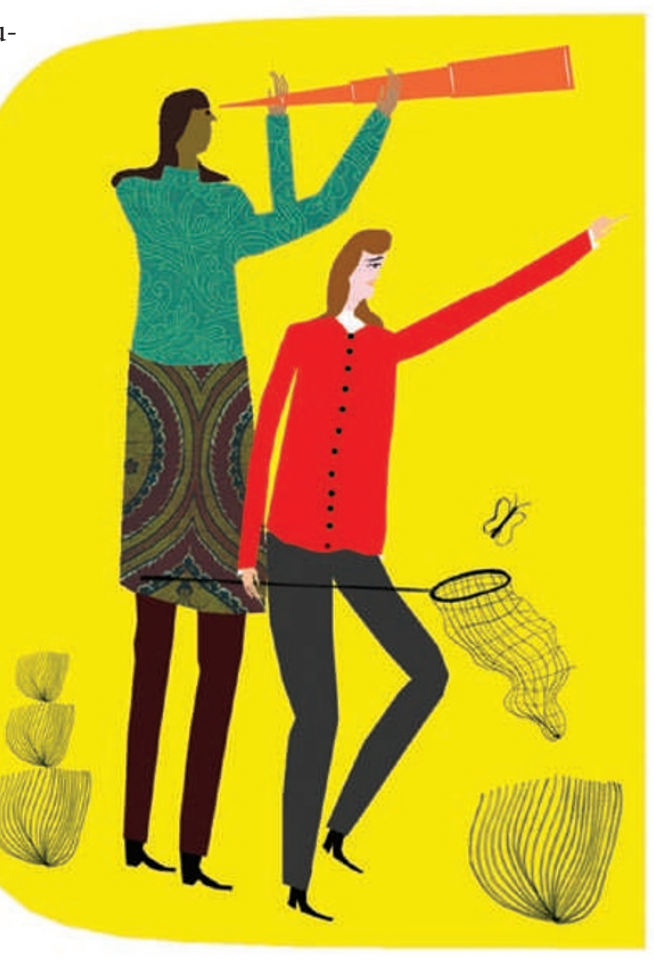

revenues. A similar calculus drives the recruitment of star faculty and the intellectual property they generate. Knowledge is a public good, but Wildavsky demonstrates that it is also a private good and that cash-strapped universities may end up compromising other values, such as the principles of non-discrimination or academic freedom, in a global quest to "fill the budget hole".

Comparing global universities to multinational corporations, Wildavsky traces their feverish pursuit of world-class status as measured by global rankings. He delights in pointing out the power of these rankings, despite their well-known limitations, such as their reliance on citation indexes that marginalize some fields of scholarship. Rankings, he says, offer "consumer information" to help parents and governments make "apples-to-apples, crossborder comparisons of educational quality" - although he stops short of showing exactly

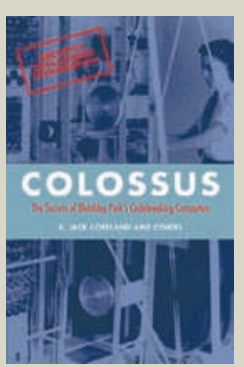

\section{Colossus: The Secrets of Bletchley Park's Codebreaking Computers}

by B. Jack Copeland and others (Oxford Univ. Press, E11.99)

This compilation of essays uses recently declassified information to tell the story of Colossus, the Second World War cryptanalysis machine and the world's first fully functioning digital computer. Jon Agar described it as "essential reading for historians of twentieth-century technology and warfare." (Nature 442, 746; 2006.)

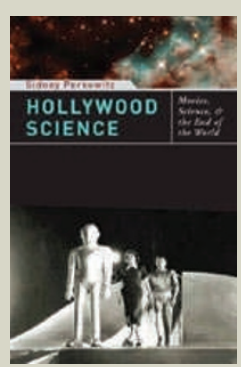

Hollywood Science: Movies, Science, and the End of the World

by Sidney Perkowitz (Columbia Univ. Press, \$18.95)

Despite the scientific inaccuracies and geek stereotypes in many films, "Hollywood Science reveals, perhaps inadvertently, what scientists owe to film: a kindling of interest in scientific concepts that shadows the audience," wrote Emma Marris (Nature 450, 481-482; 2007). 
how rankings measure quality.

Wildavsky's style is gripping and urgent. Although he exaggerates the "irrelevance" of national boundaries in higher education visa restrictions, patent laws and constraints on security-related research all prove the continued relevance of borders in a knowledge economy - his point that the forces of globalization will profoundly shape the future of higher education cannot be ignored. Not everyone will share Wildavsky's faith that a "free trade in minds" will lead to equitable, or economically beneficial, outcomes. However, we must all grapple with his view that knowledge is a commodity, and universities, if they wish to survive, must treat it as such. Adam R. Nelson is associate professor of educational policy studies and history at the University of Wisconsin-Madison, Madison, Wisconsin 53715, USA.

e-mail:anelson@education.wisc.edu

\section{Why fairness pays}

\section{The Calculus of Selfishness \\ by Karl Sigmund \\ Princeton University Press: 2010. 192 pp. $\$ 35.00, £ 24.95$}

Why would two drivers caught in a snowdrift both shovel snow to clear a route, rather than wait for one to do it? Or, given $\$ 10$ to split with someone however you like provided they accept your offer, why are you more likely to give them $\$ 5$ than $\$ 1$ ? You could keep $\$ 9$, knowing that your ultimatum is better for them than the $\$ 0$ you would both get if they refuse. Why does it pay to be fair?

Understanding the evolution of cooperation is one of this century's foremost scientific challenges. It is also an exercise in game theory, the mathematical modelling of strategic interaction. Since 2000, several international meetings and multi-authored volumes have focused on the problem, and some consensus has emerged. Animals, especially humans, are far more cooperative than game theory has predicted. However, existing models exclude important factors, such as group dynamics and emotions, which are capable of sustaining commitments. We need a new kind of game theory to capture, among other things, variation in psychological traits, cultural forces and network structure.

Nevertheless, Karl Sigmund opts to "neglect" these three factors in The Calculus of Selfishness. It is a book about the old kind of game theory. Sigmund focuses on "simple models of social dilemmas", such as the 'snowdrift' and 'ultimatum' games mentioned above. In exploring "reciprocity between selfinterested individuals", he adopts a broad interpretation that includes third parties as potential donors or recipients of help. He demonstrates how concern for one's own reputation can help preserve norms of community or fairness, such as the fair split that is usually observed in ultimatum experiments. If I know that you reject unfair ultimata, then I will hesitate to propose one.

With collaborators from Vienna, Sigmund has pioneered the development of evolutionary game dynamics. This thought-provoking
"Animals, especially humans, are far more cooperative than game theory has predicted." book is a distillation of his many influential contributions to the field. It is a showcase of clever models and elegant mathematics, replete with sometimes counterintuitive insights. For example, the option to abstain from a joint effort when it seems unpromising can help to enforce cooperation based on sanctioning; and a selfish urge to exploit others, whenever one can get away with it, can boost the welfare of all by ensuring a supply of retaliators.

Sigmund's expansive introduction contains no equations. But a full appreciation of the remaining chapters demands significantly more than "a modicum of elementary mathematics". Nonetheless, the book will appeal to practitioners of behavioural or experimen-

tal economics, whose work suffuses the models; and to those who seek an upto-date assessment of how much progress the old kind of game theory has already achieved towards understanding cooperation.

The new kind of game theory, if it takes hold, will view strategically interacting populations as complex adaptive systems, and will rely increasingly on computer simulations. It will account for group, coalition and alliance formation across multiple scales of space, time and connectivity. It will also allow for personality to influence role and strategy in alliance-formation games, for example, the expected benefit of joining a group may be constrained by the perceived harmony of the resulting personality mix. Yet the new kind of game theory will never quite supplant the old, which when artfully used, as throughout Sigmund's book, affords insights that are hard to come by any other way.

Mike Mesterton-Gibbons is professor of mathematics at Florida State University, Tallahassee, Florida 32306-4510, USA, and author of An Introduction to Game-Theoretic Modelling.

e-mail:mesterto@math.fsu.edu

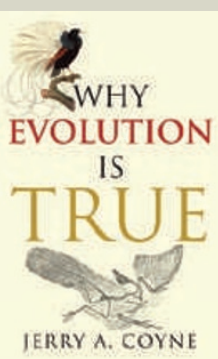

\section{Why Evolution Is True}

by Jerry A. Coyne (Oxford Univ. Press, E8.99)

Jerry Coyne demonstrates the strength of evolutionary biology in a clear and accessible manner. Reviewer Xu Xing wrote: "He uses multiple strands of data in such a clear and sometimes humorous way that an open-minded reader can hardly avoid learning a great deal about evolution: from feathered dinosaurs to vestigial organs." (Nature 462, 988; 2009.)

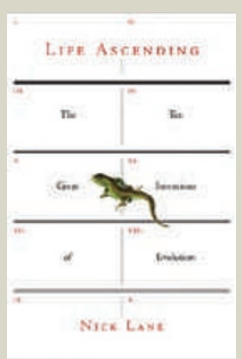

Life Ascending: The Ten Great Inventions of Evolution

by Nick Lane (Profile Books, $€ 9.99$ )

Nick Lane picks ten of evolution's key inventions - including sex, death and photosynthesis - to discuss how they arose, what they mean and why they revolutionized the living world. Wrote Lewis Wolpert of the hardback edition: "Not everyone will agree with his choice ... similar to life itself, the book is full of surprises." (Nature 460, 460; 2009.) 